\title{
Short-term stratospheric ozone fluctuations observed by GROMOS microwave radiometer at Bern
}

\author{
Lorena Moreira $^{1^{*}}$ (D) Klemens Hocke ${ }^{1,2}$ and Niklaus Kämpfer ${ }^{1,2}$
}

\begin{abstract}
The ground-based millimeter wave ozone spectrometer (GROMOS) has been continually measuring middle atmospheric ozone volume mixing ratio profiles above Bern, Switzerland $\left(46.95^{\circ} \mathrm{N}, 7.44^{\circ} \mathrm{E}, 577 \mathrm{~m}\right)$, since 1994 in the frame of NDACC. The high temporal resolution of GROMOS (30 min) allows the analysis of short-term fluctuations. The present study analyses the temporal perturbations, ranging from 1 to $8 \mathrm{~h}$, observed in stratospheric ozone from June 2011 to May 2012. The short-term fluctuations of stratospheric ozone are within 5\%, and GROMOS appears to have relative amplitudes stable over time smaller than $2 \%$ at $10 \mathrm{hPa}(32 \mathrm{~km})$. The strongest natural fluctuations of stratospheric ozone (about $1 \%$ at $10 \mathrm{hPa}$ ) above Bern occur during winter due to displacements and deformations of the polar vortex towards mid-latitudes.
\end{abstract}

Keywords: Microwave radiometry, Stratospheric ozone, Polar vortex, Atmospheric variability

\section{Introduction}

Even though ozone is a minor constituent in the atmosphere, it is a component of major interest. Stratospheric ozone filters most of the UV-B radiation from the Sun and thus allows life on Earth. High-resolution observations of minor constituents in the middle atmosphere often reveal small-scale perturbations (present in the horizontal, in the vertical and in time) overlaid upon the mean background distribution (Eckermann et al. 1998). Atmospheric waves were identified as an important source of such variability (Zhu and Holton 1986; Appenzeller and Holton 1997; Eckermann et al. 1998; Calisesi et al. 2001; Fritts and Alexander 2003; Moustaoui et al. 2003; Hocke et al. 2006; Noguchi et al. 2006; Flury et al. 2009; Chane et al. 2016). For example, the wintertime Arctic middle atmosphere is characterised by the presence of large amplitude planetary Rossby waves that often interact with the stratospheric polar vortex and trigger sudden stratospheric warming (SSW) events (Chandran et al. 2013). These events are characterised by a sudden

\footnotetext{
*Correspondence: Iorena.moreira@iap.unibe.ch

1 Institute of Applied Physics, University of Bern, Bern, Switzerland Full list of author information is available at the end of the article
}

increase in the temperature and a reversal of the zonal wind. The effect in ozone at mid-latitudes is depletion in the lower and upper stratosphere. The depletion in lower stratospheric ozone is due to transport of ozone poor air from the polar vortex, whereas the ozone depletion in the upper stratosphere is caused by the sudden increase in temperature (Flury et al. 2009). Gravity waves (GW) may also play a role in forcing of SSW when propagating into the stratosphere as a consequence of variations in the tropopause jet during instabilities in the upper troposphere (Flury et al. 2010; Yamashita et al. 2010). Midlatitude gravity waves produce periodic fluctuations of ozone volume mixing ratio in the upper stratosphere and lower mesosphere (Hocke et al. 2006) possibly due to vertical advection of air parcels by gravity waves (Zhu and Holton 1986; Eckermann et al. 1998). Another example is, for instance, horizontal mixing processes through the transport barriers, either by small-scale structures (filaments or laminae) or by large-scale structures (streamers), are thought to play a significant role in the variability of atmospheric trace gases in the middle stratosphere (Krüger et al. 2005). Atmospheric soundings at middle and high latitudes frequently disclose enhancements or depletions of lower stratospheric ozone confined to 
narrow vertical layers (Eckermann et al. 1998). These structures are known as filaments or laminae, and are mainly observed at the edge of the polar vortex in the lower stratosphere (tropopause-25 km), generated by planetary Rossby wave breaking (Eckermann et al. 1998; Krüger et al. 2005). Regarding the large-scale structures, there are two types of stratospheric streamers: the tropical-subtropical streamer and the polar vortex streamer (Waugh 1993; Offermann et al. 1999; Manney et al. 2001; Eyring et al. 2003; Krüger et al. 2005). These structures transport tropical-subtropical and polar vortex air masses into mid-latitudes more frequently during Arctic winter. The breaking of planetary Rossby waves at the edge of the polar vortex (polar vortex streamers) or at the edge of the tropics (tropical-subtropical streamers) seems to be linked with the transport of air masses into mid-latitudes (Krüger et al. 2005). The observed effect in ozone is the meridional mixing of ozone (Eyring et al. 2003). The stratospheric streamers occur preferentially at higher altitudes above $20 \mathrm{~km}$, in the middle stratosphere, in contrast to filaments (laminae) which occur below 25 $\mathrm{km}$, in the lower stratosphere (Krüger et al. 2005). Nevertheless, a streamer can eventually develop into a filament-like structure (Waugh 1993; Krüger et al. 2005).

Many of the instruments used for measuring the composition of the atmosphere make use of the spectral properties of its constituent gases (Parrish 1994). Millimeter wave radiometry is a well-established tool for the monitoring of atmospheric species. It is a passive remote sensing technique which detects radiation emitted by rotational transitions of molecules in the atmosphere. The spectral analysis of the pressure broadened lines emitted by the species under analysis permits the retrieval of the vertical profile from the lower stratosphere to the mesosphere (20-70 km) (Kämpfer 1995). The technique enables day-round measurements as there is no reliance on the Sun as a source and under nearly all weather conditions. In addition, microwave radiometry provides high temporal resolution. In the present study, we take advantage of this feature and we analyse the short-term fluctuations (1-4 h) of stratospheric ozone measured by the GROMOS radiometer. The aim of this analysis is to initiate a new field of study regarding the short-term stratospheric perturbations in trace constituents, ozone in our case, since we are not aware of any other studies on this topic, except for Hocke et al. (2006), but this study is restricted to mesospheric fluctuations. The characterisation of the short-term ozone fluctuations can lead to a better understanding of the role of atmospheric waves and nonlinear wave-wave interactions to induce perturbations in trace gas profiles.

"The GROMOS radiometer" section describes the GROMOS instrument along with an overview of the retrieval method, which has been modified to enable the study of these small-scale perturbations. In "Method" section is explained the method used for this purpose. "Results and discussion" section shows the results obtained along with a discussion on the geophysical causes of short-term mid- and upper stratospheric ozone fluctuations. And finally "Conclusions" section offers some concluding remarks.

\section{The GROMOS radiometer}

GROMOS (ground-based millimeter wave ozone spectrometer) was constructed by the Institute of Applied Physics of the University of Bern. The instrument has been operated in Bern $\left(46.95^{\circ} \mathrm{N}, 7.44^{\circ} \mathrm{E}, 577 \mathrm{~m}\right)$ since November 1994 in the scope of the network for the detection of atmospheric composition change (NDACC). NDACC is an international global network of more than 80 stations making high-quality measurements of atmospheric composition that began official operations in 1991 (Mazière et al. 2017). The GROMOS microwave radiometer detects the thermal emission of the pressure broadened rotational transition of ozone at $142.175 \mathrm{GHz}$. The spectrum measured by the instrument is given in terms of brightness temperature. The brightness temperature is the physical temperature at which a perfect blackbody would emit the same power as it is measured by the instrument. For a review of technical details on the instrument, we refer to, for instance, Moreira et al. (2015) or Peter (1997).

\section{Retrieval technique}

The shape of the spectral line measured by the instrument contains information on the vertical distribution of the emitting molecule, because of the pressure broadening (Parrish 1994). Therefore, the vertical distribution of ozone VMR can be retrieved from the observed emission line shape by means of radiative transfer in a model atmosphere and an optimal estimation method. The atmospheric radiative transfer simulator (ARTS2) (Eriksson et al. 2011) is used as forward model to simulate atmospheric radiative transfer and calculate an ozone spectrum for the modelled atmosphere by using an a priori ozone profile. The inversion is done through the accompanying MATLAB package Qpack2 (Eriksson et al. 2005), which uses the optimal estimation method (OEM) (Rodgers 1976) to derive the best estimate of the vertical profile by combining the measured and modelled spectra. During the inversion process, a priori information is required. The a priori ozone profiles are from a monthly climatology from reanalysis data of the European Centre for Medium-range Weather Forecasts (ECMWF) up to $70 \mathrm{~km}$ and extended above by a monthly ozone climatology from observations close to Bern of the satellite 
microwave limb sounder Aura/MLS. In the present study, we use the retrieval version 111 which is optimised for the retrieval of short-term ozone fluctuations since we take into account uncertainties of the retrieved ozone resulting from the tropospheric opacity as described later in more detail. The a priori covariance matrix of retrieval version 111 is $2 \mathrm{ppm}$ for the diagonal elements, and the values decay exponentially with a correlation length of 3 $\mathrm{km}$ for the off-diagonal elements.

Figure 1 shows the a priori (green line-left panel) and the retrieved profile (blue line-left panel) recorded at noon the 28 August 2011 obtained by the retrieval version 111. The averaging kernels (AVKs) and the area of the AVKs, the measurement response (MR), are represented in the middle panel. The AVKs are multiplied by 4 in order to be displayed along with the MR (red linemiddle panel). The AVK-lines are the grey lines except for some altitude levels, which are in different colours: orange for $20 \mathrm{~km}$, green for $30 \mathrm{~km}$, magenta for $40 \mathrm{~km}$, cyan for $50 \mathrm{~km}$, black for $60 \mathrm{~km}$ and blue for $70 \mathrm{~km}$. The a priori contribution to the retrieved profile can be estimated by 1 minus the area of the AVKs, the so-called measurement response (MR-middle panel). A reliable altitude range for the retrieval is considered where the MR is larger than 0.8 , which corresponds to an a priori contribution smaller than $20 \%$. The vertical resolution (cyan line-right panel) is quantified by the full width at half maximum of the AVKs. The vertical resolution of GROMOS lies from 10 to $18 \mathrm{~km}$ in the stratosphere and up to $20 \mathrm{~km}$ in the middle mesosphere. The same panel shows the altitude peak (magenta line-right) of the corresponding kernels, and as it can be observed in the coloured AVK-lines, the AVKs peak at its nominal altitude for the considered vertical range.

The signal from the stratosphere detected by the instrument is attenuated by the troposphere, mainly due to water vapour content. Tropospheric water vapour significantly influences the measured ozone spectrum by increasing the continuum emission and attenuating the stratospheric ozone emission line. Accordingly, it is important to correct the measured spectra for the tropospheric effect. The tropospheric correction depends upon the opacity of the troposphere. The transmission factor:

$$
\begin{gathered}
e^{-\tau}=\frac{T_{\mathrm{b}}\left(z_{0}\right)-T_{\text {trop }}}{T_{\mathrm{b}}\left(z_{\text {trop }}\right)-T_{\text {trop }}} \\
T_{\text {trop }}=T_{\text {surface }}+\Delta T
\end{gathered}
$$

where $\tau$ is the tropospheric opacity that can be calculated from the wings of the measured spectrum where the wings are about $0.5 \mathrm{GHz}$ away from the ozone line centre. $T_{\text {trop }}$ is the mean tropospheric temperature (Eq. 2), which is estimated according to a linear model proposed by
Ingold et al. (1998), considering the surface air temperature $\left(T_{\text {surface }}\right)$ measured at a nearby weather station and a temperature offset $\Delta T=-10.4 \mathrm{~K}$, depending on the frequency range (142 GHz) and on the altitude (577 m.a.s.l). $T_{\mathrm{b}}\left(z_{\text {trop }}\right)$ is the brightness temperature that the radiometer would measure at the tropopause level. $T_{\mathrm{b}}\left(z_{0}\right)$ is the brightness temperature measured at ground level, and it is estimated from the off-resonance emission at the wings of the spectrum. The brightness temperature of the wings corresponds to the continuum emission due to tropospheric oxygen and water vapour. The larger (smaller) the tropospheric opacity or the smaller (larger) the transmittance of the signal through the troposphere, the larger (smaller) the tropospheric correction. The correction of the tropospheric contribution consists of scaling the amplitude of the measured line spectrum, as if it would be measured at tropopause level in an isothermal troposphere with a mean tropospheric temperature, $T_{\text {trop }}$.

Nevertheless, because of the tropospheric correction the noise in the spectrum is magnified. In Fig. 2 are shown two measurements of the GROMOS spectra binned in frequency, one for a clear sky case and another for a cloudy sky case. The GROMOS spectra are binned in time and frequency. The binning in time is $30 \mathrm{~min}$. The fast Fourier transform spectrometer (FFTS) has around 32,768 channels, and after the binning in frequency the number of points in frequency is 54 with higher frequency resolution in the line centre compared to the line wings. In the clear sky case, the brightness temperature $\left(T_{\mathrm{b}}\right)$ is around $90 \mathrm{~K}$ at the peak $(142.175 \mathrm{GHz})$, whereas in the cloudy sky case the brightness temperature is quite high, $200 \mathrm{~K}$ at the peak and $192 \mathrm{~K}$ on the wings. Therefore, when at a glance the sky is cloudy, the instrument measures higher brightness temperatures. In the second row are represented the spectra $\left(T_{\mathrm{b}}^{\prime}\right)$ of both cases after the application of the tropospheric correction. The consequence of a larger tropospheric correction is what we observe in the third row, where the error of the brightness temperature $\left(\Delta T_{\mathrm{b}}^{\prime}\right)$ for both cases is represented. $\Delta T_{\mathrm{b}}^{\prime}$ in the cloudy sky case is larger than in the clear sky case, due to the amplification of the error by the tropospheric correction. Accordingly, the retrieval error of the measurements is larger when the tropospheric correction is larger, i.e. smaller tropospheric transmittance. Normally, the GROMOS retrieval is performed with a constant error of $\Delta T_{\mathrm{b}}^{\prime}=0.8 \mathrm{~K}$, but retrieval version 111 of this study has a variable error depending on the tropospheric transmission:

$$
\Delta T_{\mathrm{b}}^{\prime}=0.5 \mathrm{~K}+\frac{\Delta T_{\mathrm{b}}}{e^{-\tau}}
$$

the error of the measured brightness temperature, $\Delta T_{\mathrm{b}}$, is given by the radiometer equation: 


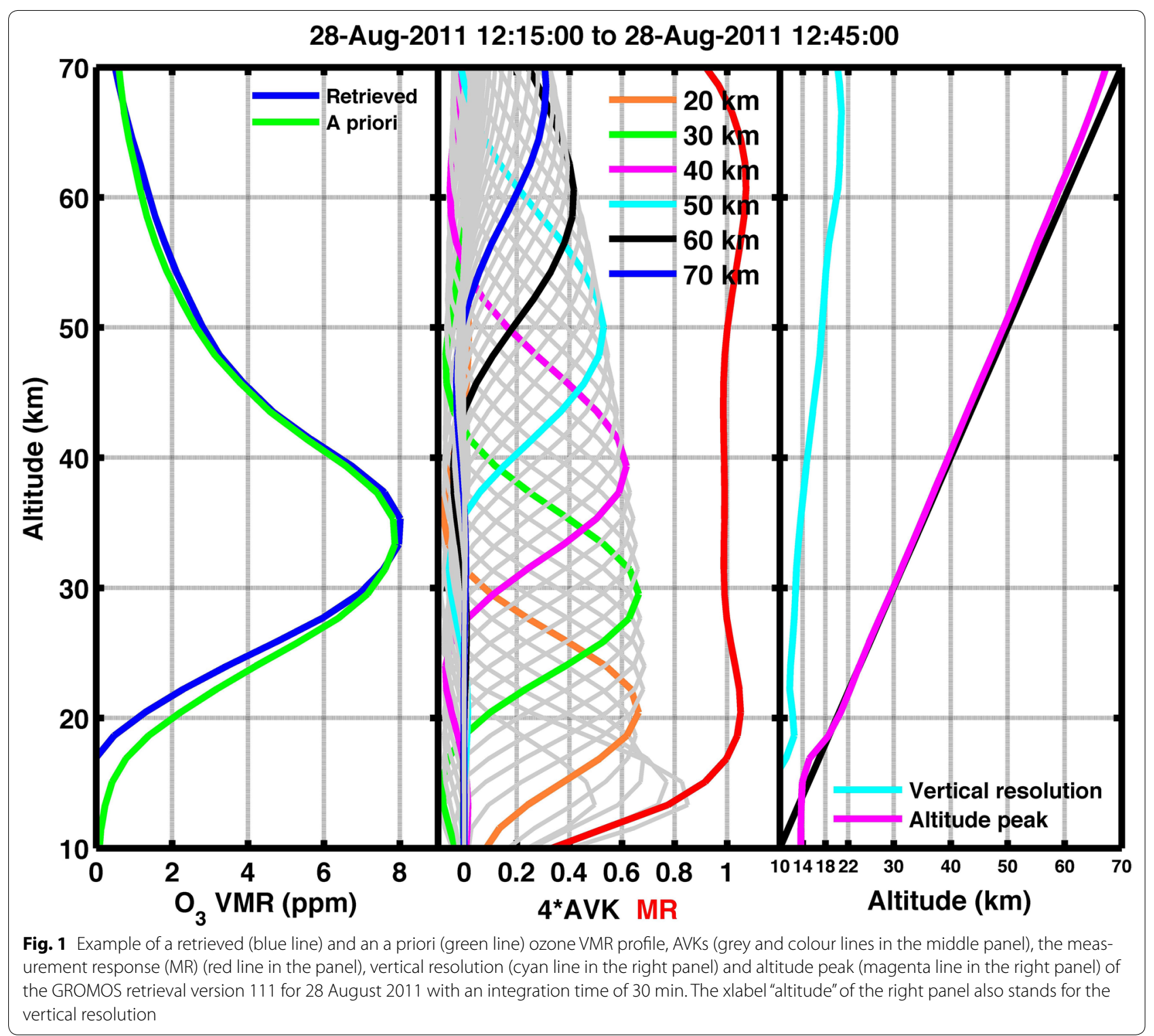

$$
\Delta T_{\mathrm{b}}=\frac{T_{\mathrm{b}}+T_{\mathrm{rec}}}{\sqrt{\Delta f \cdot t_{\mathrm{int}}}}
$$

The radiometer equation gives the resolution of the radiation measured, which is determined by the bandwidth of the individual spectrometer channels $(\Delta f)$, by the integration time $\left(t_{\text {int }}\right)$ and by the total power measured by the spectrometer. A constant error of $0.5 \mathrm{~K}$ is considered as a systematic bias of the spectra, due to spectroscopic errors and the water vapour continuum. As it is shown in Fig. 2, the error of the brightness temperature $\left(\Delta T_{\mathrm{b}}\right)$ is of the order of a few Kelvins in the line centre and $0.5 \mathrm{~K}$ in the line wings of the spectrum. Therefore, the measurement noise $\left(\Delta T_{\mathrm{b}}^{\prime}\right)$ depends on the frequency due to different spectral binning and on the tropospheric transmittance. $\Delta T_{\mathrm{b}}^{\prime}$ is larger in the ozone line centre since the binning is only over a few channels at the ozone line centre, while the binning in the line wings is over several hundred channels or more. Thus, the thermal noise is reduced in the ozone line wings by averaging over a high number of channels. This is a more realistic approach for the retrieval than considering a constant measurement noise, resulting in an improvement in the retrieved ozone VMR in the lower stratosphere.

\section{Methods}

The present study analyses the short-term fluctuations in stratospheric ozone measured by the GROMOS radiometer from June 2011 to May 2012. We selected this time interval since it covers a full year with the winter in 


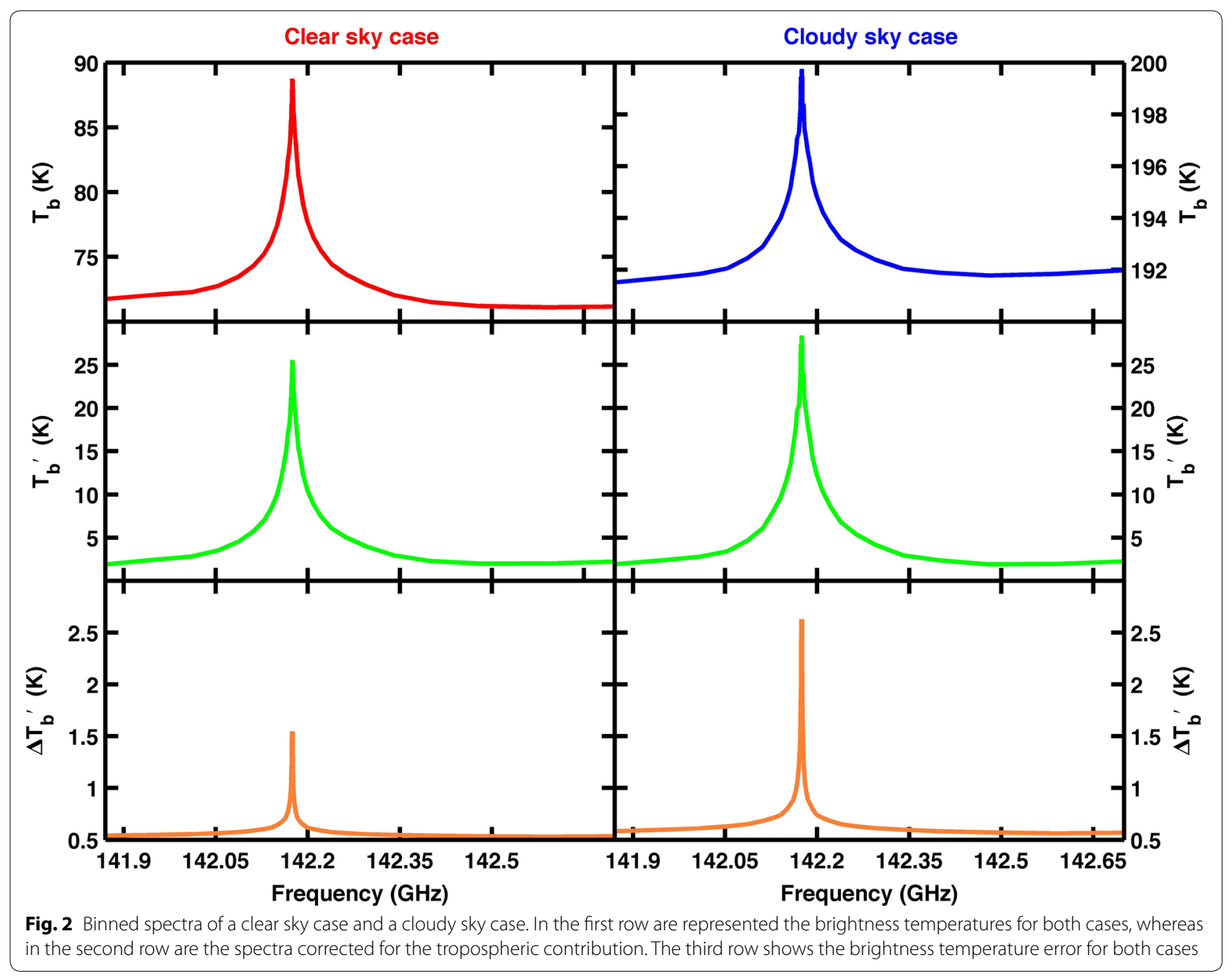

the centre. Further, the disturbance of the Northern polar vortex was relatively simple in winter 2011/2012 which is mainly characterised by a minor sudden stratospheric warming in mid-January 2012 (Chandran et al. 2013). Thus, the attribution between the polar vortex disturbance and the behaviour of the short-term ozone fluctuations above Bern is easier in this year compared to other years.

We have used the standard deviation, calculated after the removing of the linear trend, of 8 consecutive ozone profiles within a time window of about $4 \mathrm{~h}$ as a proxy for the strength of the fluctuations. The standard deviation is a measure that is used to quantify the amount of dispersion of a set of data from its mean. The deviation is higher when the data are spread out to the mean, and in our case indicates stronger fluctuations. Since the sampling rate is $30 \mathrm{~min}$, oscillations with periods of $1 \mathrm{~h}$ (Nyquist period) to about $8 \mathrm{~h}$ will contribute to the calculated standard deviation. An example of these standard deviations is presented in Fig. 3. First panel of Fig. 3 shows the ozone VMR (ppm) through the blue line, the mean of 8 consecutive ozone values (red line) and the standard deviation calculated every 8 ozone values after the removal of the linear trend (red area) at $10 \mathrm{hPa}$ for a time interval of nearly 2 days at the beginning of June 2011. The second panel of Fig. 3 displays the tropospheric transmittance observed for the same interval as the upper panel. This tropospheric transmittance corresponds to cloudy sky cases, in which tropospheric corrections were performed. We cannot find a clear relation between the tropospheric transmittance (green line) and the fluctuations (red area). Later, we quantify that the uncertainty of the ozone retrieval only depends marginal on the tropospheric transmission. We conclude from Fig. 3 that GROMOS measurements are stable over time with a standard deviation around $2 \%(0.15 \mathrm{ppm})$ at $10 \mathrm{hPa}(32 \mathrm{~km})$. Generally, the relative amplitudes are stable over time within $5 \%$ in the stratosphere (from 20 to $50 \mathrm{~km}$ altitude). In addition, Fig. 3 shows that the amplitudes of natural short-term ozone fluctuations are smaller than $2 \%$ at $10 \mathrm{hPa}$ for the time interval shown, 


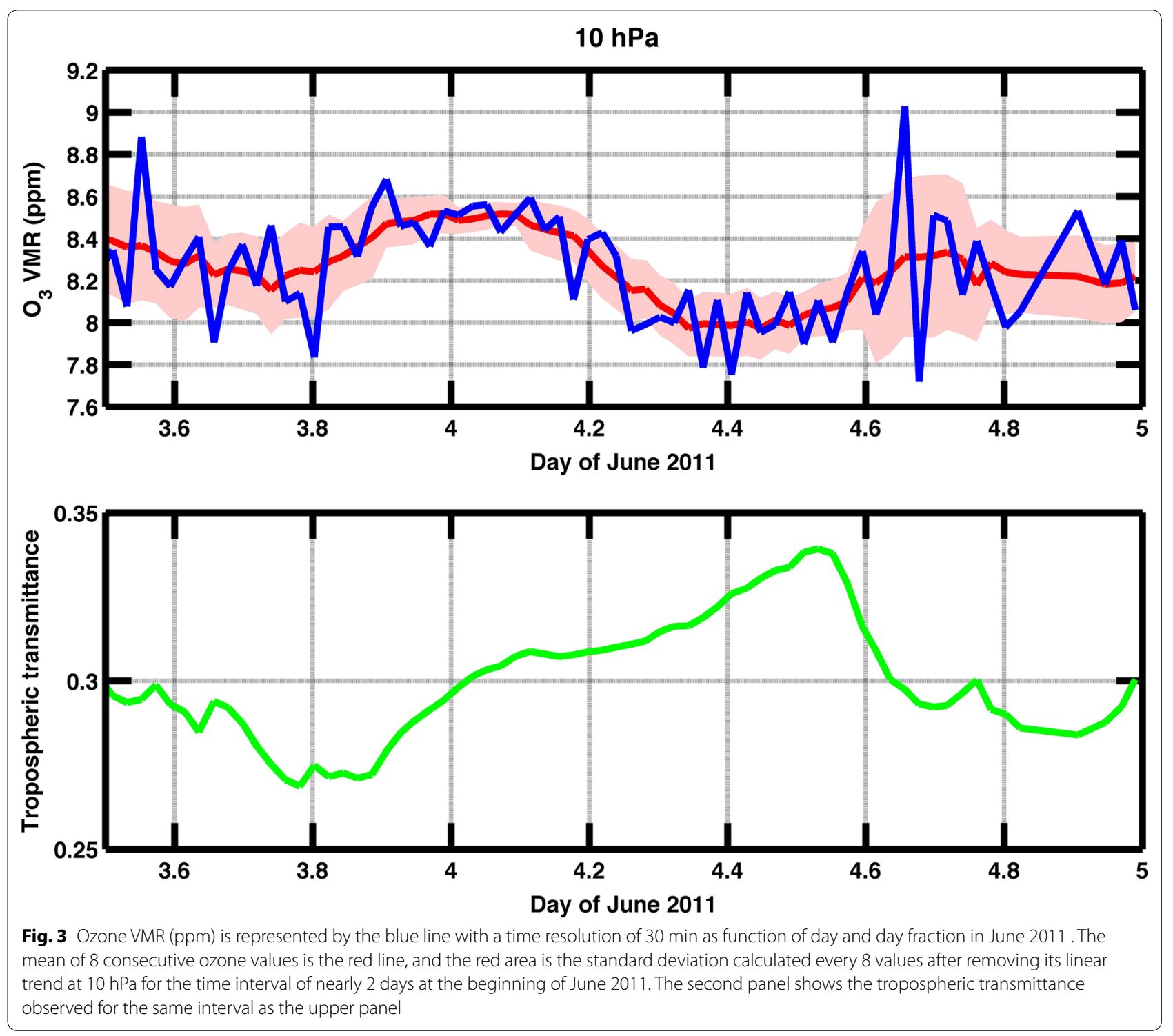

since the fluctuations also contain the influence of the random retrieval error. The resulted time series are due to natural short-term fluctuations and to some random retrieval errors. The random retrieval error includes the thermal noise on the spectra due to the receiver noise, which propagates into the ozone profiles. Unfortunately, this contribution is impossible to discriminate from the retrieval error; nevertheless, we did not find any artificial periodicity in the temporal range of our study (from 1 up to $8 \mathrm{~h}$ ). Since the mid-latitude stratosphere is known to be quiet during summer, it can be assumed that the retrieval error is mainly due to the random retrieval error (thermal receiver noise) in summer.

We focus our study on the $10 \mathrm{hPa}$ pressure level in the middle stratosphere where the ozone retrieval is most reliable since the ozone volume mixing ratio is high at
$10 \mathrm{hPa}$, and the influence of the water vapour continuum is smaller at $10 \mathrm{hPa}$ than in the lower stratosphere at 50 $\mathrm{hPa}$. The goal is to investigate whether natural short-term ozone fluctuations can occur exceeding the $2 \%$ standard deviation level. These disturbances are believed to occur naturally in the stratosphere primarily due to atmospheric waves propagating from the troposphere into the stratosphere during winter, since the winds are eastward at all altitudes levels and also due to the winter stratosphere which is more dynamically driven than radiatively driven (Zhu and Holton 1986; Appenzeller and Holton 1997; Eckermann et al. 1998; Calisesi et al. 2001; Fritts and Alexander 2003; Moustaoui et al. 2003; Hocke et al. 2006; Noguchi et al. 2006; Flury et al. 2009; Chane et al. 2016).

The short-term stratospheric ozone fluctuations $\left(\sigma_{\text {strato }}\right)$ can also be affected by the tropospheric correction, since 
the retrieval error of the measurements is larger when the tropospheric correction is larger. This contribution can be estimated; therefore, we have calculated the influence of the tropospheric correction in the retrieved profiles. To bring about this requirement, we consider during the retrieval procedure that the brightness temperature error depends on the transmission factor (Eq. 3). In Fig. 4, we can observe the effect of the tropospheric transmittance in the random retrieval error of the profile, which is provided by the optimal estimation method (the smoothing error is not considered), at different pressure levels for the period from June 2011 to May 2012. The retrieval error is smaller when the tropospheric transmittance is larger. However, this effect is smaller than $0.02 \mathrm{ppm}$ at 10 $\mathrm{hPa}$. The green lines are the mean values of the retrieval error and of the tropospheric transmittance, and the red lines are the values of the second-degree polynomial regression of both variables evaluated at the tropospheric transmittance values.

In order to quantify the fluctuations generated by the tropospheric correction $\left(\bar{\sigma}_{\text {retrieval }}\right)$, we performed a second-degree polynomial regression $\left(\sigma_{\text {retrieval }}(t)=p_{1} t^{2}+p_{2} t+p_{3}\right)$ between the retrieval error $\left(\sigma_{\text {retrieval }}\right)$ and the tropospheric transmittance $(t)$. The coefficients $\left(p_{1}, p_{2}, p_{3}\right)$ resulted are evaluated at the mean of 8 consecutive values of the tropospheric transmittance $(\bar{t})$ to obtain the $\bar{\sigma}_{\text {retrieval }}(\bar{t})=p_{1} \bar{t}^{2}+p_{2} \bar{t}+p_{3}$.

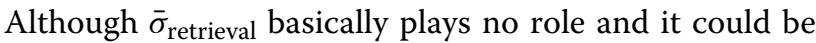
neglected, we consider it in the calculation of the stratospheric fluctuations $\left(\sigma_{\text {strato }}=\sqrt{\sigma_{\text {total }}^{2}-\bar{\sigma}_{\text {retrieval }}^{2}}\right)$.

\section{Results and discussion}

Figure 5 shows in the first panel the total short-term stratospheric ozone relative fluctuations contained in the GROMOS data in magenta $\left(\sigma_{\text {total }}\right)$, which is covered by the stratospheric relative fluctuations $\left(\sigma_{\text {strato }}\right)$ in blue, as they are practically identical, and the relative fluctuations caused by the tropospheric opacity $\left(\bar{\sigma}_{\text {retrieval }}\right)$ in red, in per cent at $10 \mathrm{hPa}(32 \mathrm{~km})$ for the period from June 2011 to May 2012. $\bar{\sigma}_{\text {retrieval }}$ is rather small, and hence, the tropospheric transmission on the retrieval noise has a minor effect on the observed temporal fluctuations of stratospheric ozone. Nevertheless, a random retrieval error is still included in $\sigma_{\text {strato. }}$ Therefore, the blue line is the
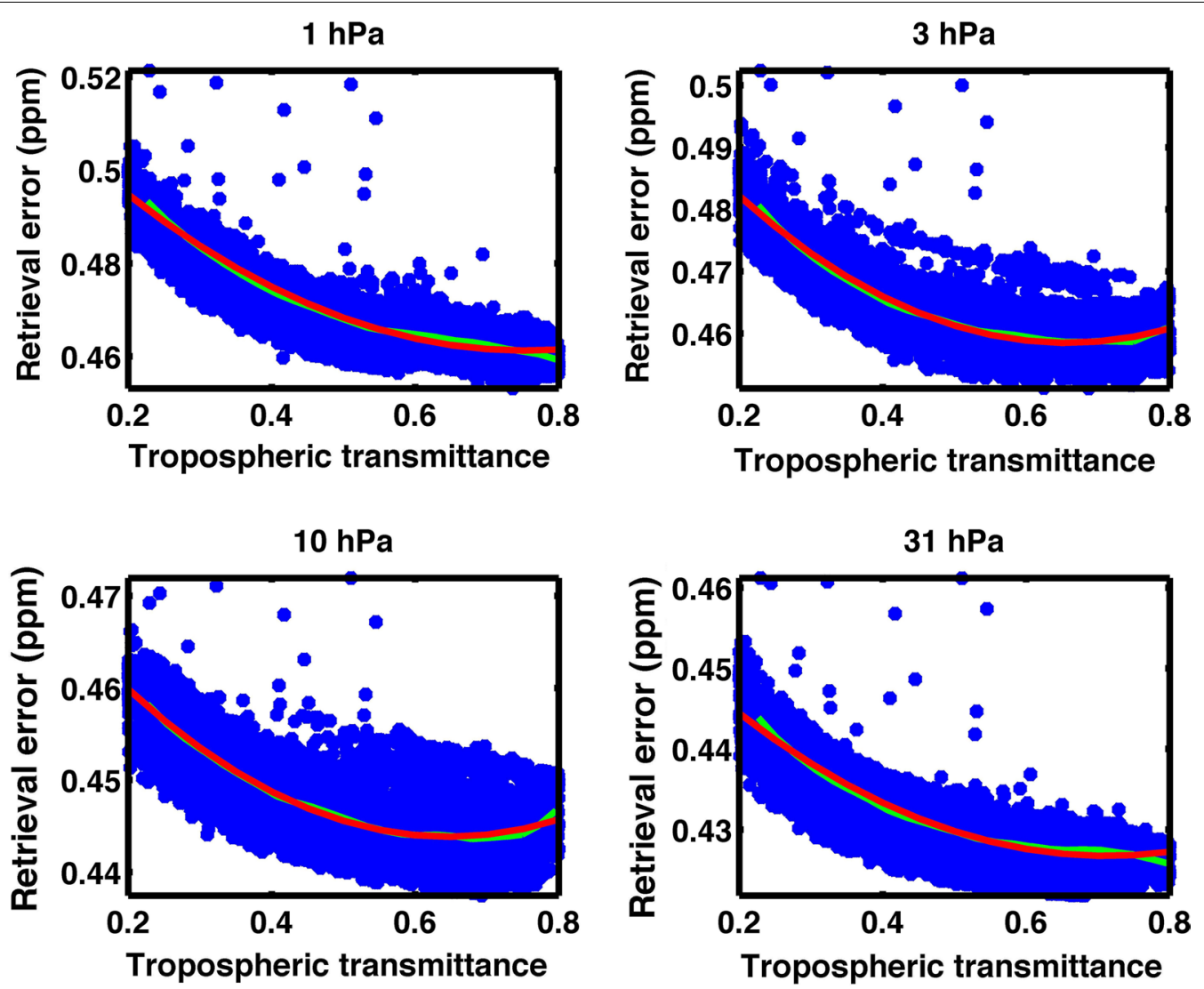

Fig. 4 Scatter plot of the tropospheric transmittance and retrieval error at different pressure levels during the time interval from June 2011 to May 2012. The green lines are the mean values of both variables and the red lines are the values of the second-degree polynomial regression of both variables evaluated at the tropospheric transmittance values 
sum of the natural ozone fluctuations and the unknown influence of the random noise on the ozone time series. However, we learn from Fig. 5 that an upper limit to this contribution can be set, around $2 \%$. In addition, there seems to be a temporal evolution of $\sigma_{\text {strato, }}$ which is more likely due to natural ozone fluctuations, since the receiver noise is constant in time, usually around $2500 \mathrm{~K}$. The ozone fluctuations are shown in the middle stratosphere because at this level the random retrieval error is about $2 \%$, while the disturbed polar vortex edge often reaches mid-latitudes. Thus, we expect enhanced ozone fluctuations above Switzerland during times of a disturbed polar vortex. We can state from Fig. 5 that the strongest fluctuations occur during December and January, with an increase in $\sigma_{\text {strato }}$ of about $1 \%$. Up to now, the magnitude of short-term ozone fluctuations was unknown. Our study gives the result that the relative standard deviation of short-term ozone fluctuations in the vicinity of the polar vortex is about $1 \%$. Thus, our study showed that short-term ozone fluctuations of the mid-stratosphere are quite small even at the polar vortex edge. We obtained similar results for other years too.

In the second panel is represented the ozone VMR in ppm at $10 \mathrm{hPa}(32 \mathrm{~km})$ with the aim to observe its behaviour during the period under assessment. The standard deviations and the ozone VMR displayed in first and second panel of Fig. 5 have been smoothed in time by a moving average over an interval of 3-4 days. The third panel shows the geopotential height $(\mathrm{GPH})$ at $10 \mathrm{hPa}$ $(32 \mathrm{~km})$ from June 2011 to May 2012 from ECMWF reanalysis data. The stratospheric ozone fluctuations $\left(\sigma_{\text {strato }}\right)$ are larger when the GPHs are lower above our location. These lower GPHs are associated with deformations and southward excursions of the polar vortex, which are caused by planetary Rossby wave activity (Calisesi et al. 2001). The fourth panel of Fig. 5 shows the vertical wind from ECMWF reanalysis data. The strong vertical wind oscillations during December and January occur presumably because of the planetary Rossby wave breaking. In fact, Chandran et al. (2013) have reported a minor sudden stratospheric warming (SSW) in mid-January 2012. This SSW is also seen in the bottom panel which shows an increase in the relative fluctuations of potential vorticity at $10 \mathrm{hPa}$ at Bern. It is considered a minor SSW since the zonal mean wind reversal did not reach the $10 \mathrm{hPa}$ $(32 \mathrm{~km})$ level. However, we can observe its effect in the short-term stratospheric ozone fluctuations (first panel of Fig. 5) and also in ozone at $10 \mathrm{hPa}$ from ECMWF operational data (Fig. 6). Figure 6 displays plots of potential vorticity, temperature and ozone from ECMWF operational data at $10 \mathrm{hPa}$ for the 15 January 2012. From the potential vorticity plot, we know that the polar vortex is shifted southward and Bern is located inside the polar vortex. We notice an increase of about $1 \%$ in the

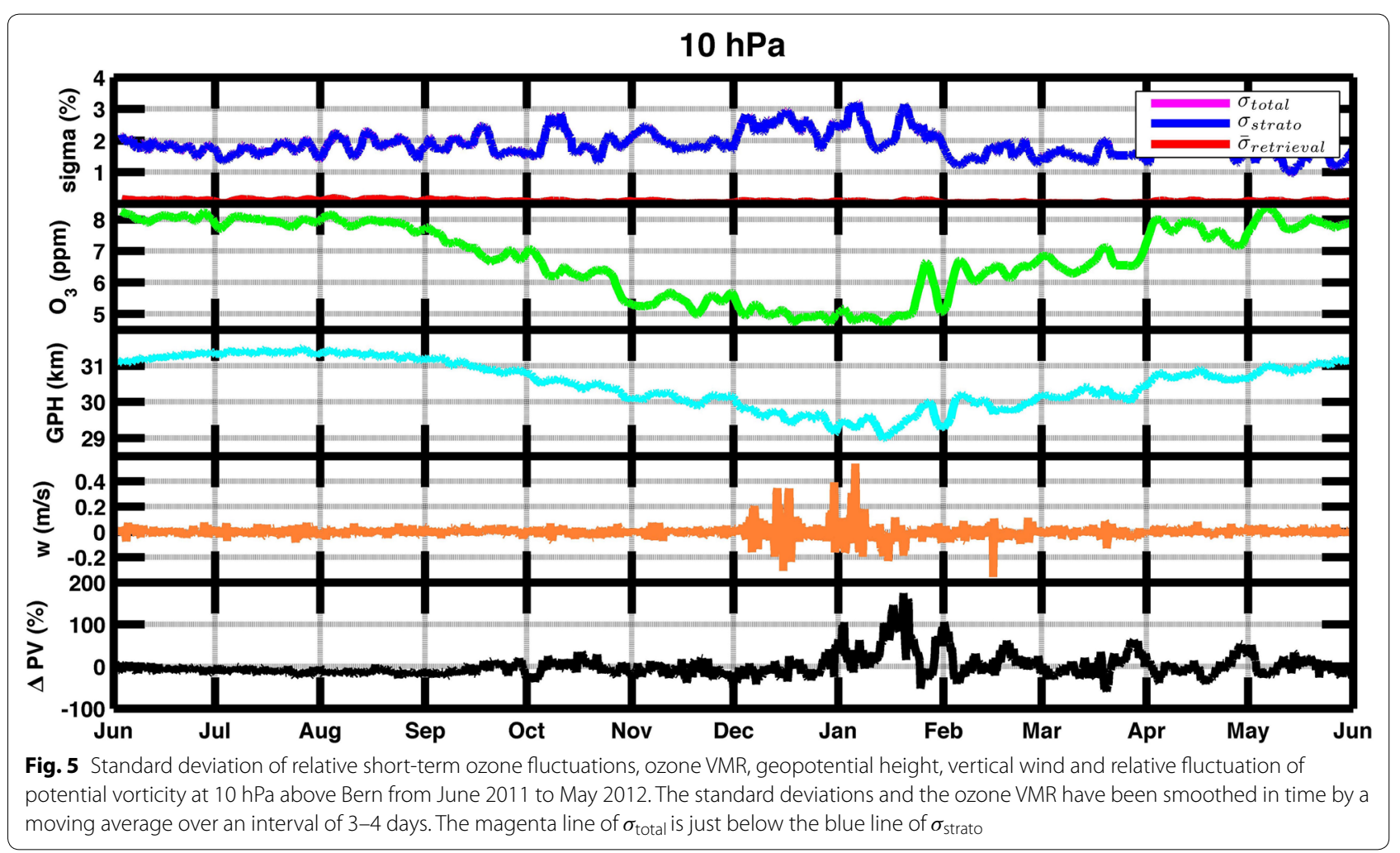



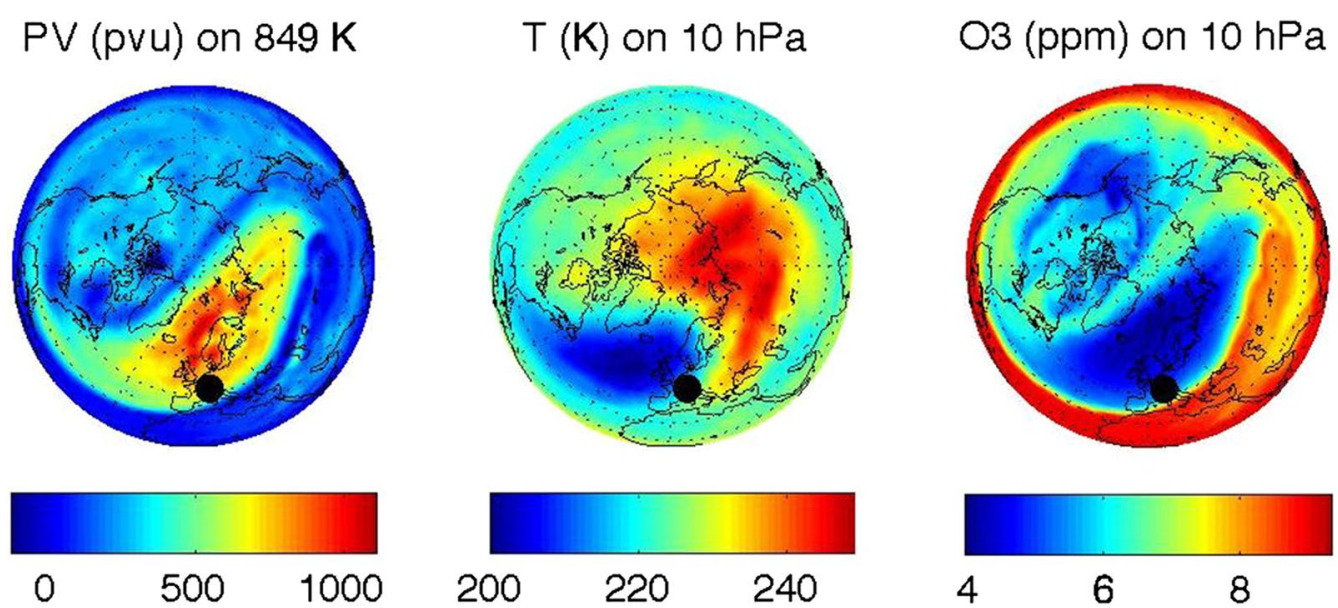

Fig. 6 ECMWF plots of potential vorticity, temperature and ozone at $10 \mathrm{hPa}$ for the northern hemisphere, for the 15 January 2012. The black dot shows the location of Bern, Switzerland

stratospheric ozone fluctuations during winter, when the polar vortex makes its incursions towards the midlatitudes. Enhanced relative standard deviations, i.e. stronger fluctuations (Fig. 5), are found when GROMOS is measuring inside the polar vortex (Fig. 6). Thus, this minor SSW seems to be the reason for the enhancement of short-term stratospheric ozone fluctuations during January 2012.

Nevertheless, the short-term stratospheric ozone fluctuations are not getting stronger than $3 \%$ in average. We would have expected that stronger amplitudes would occur at the polar vortex edge during times of breaking planetary Rossby waves.

\section{Conclusions}

The short temporal perturbations in stratospheric ozone were investigated through the data recorded by the GROMOS ground-based microwave radiometer at Bern from June 2011 to May 2012. In the present study, the retrieval takes into account the variable noise of the tropospheric corrected spectra. Accordingly, we can estimate the influence of the random retrieval error on the temporal ozone fluctuations. These ozone fluctuations only weakly depend upon the tropospheric transmittance. We find that the effect of tropospheric transmittance on the retrieval error is less than $0.02 \mathrm{ppm}$ at $10 \mathrm{hPa}$. The contribution to the stratospheric fluctuations is due to the random retrieval error (about $2 \%$ at $10 \mathrm{hPa}$ ) and to natural short-term ozone fluctuations. We find that during times of a disturbed vortex the short-term ozone fluctuations can reach a standard deviation of about $1 \%$ superposed on the random retrieval error. This is a new result which quantifies the magnitude of short-term ozone fluctuations in the wintertime mid-stratosphere at mid-latitudes.

\section{Authors' contributions}

KH performed the retrieval of the GROMOS measurements. LM carried out the data analysis and prepared the manuscript. NK is the principal investigator of the radiometry project. All authors have contributed to the interpretation of the results.

\section{Author details}

${ }^{1}$ Institute of Applied Physics, University of Bern, Bern, Switzerland. ${ }^{2}$ Oeschger Centre for Climate Change Research, University of Bern, Bern, Switzerland.

\section{Acknowlegements}

This work was supported by the Swiss National Science Foundation under Grant 200020-160048 and MeteoSwiss GAW Project: "Fundamental GAW parameters measured by microwave radiometry".

\section{Competing interests}

The authors declare that they have no competing interests.

\section{Publisher's Note}

Springer Nature remains neutral with regard to jurisdictional claims in published maps and institutional affiliations.

Received: 5 October 2017 Accepted: 25 December 2017

Published online: 11 January 2018

\section{References}

Appenzeller C, Holton JR (1997) Tracer lamination in the stratosphere: a global climatology. J Geophys Res Atmos 102(D12):13555-13569. https://doi. org/10.1029/97JD00066

Calisesi Y, Wernli H, Kämpfer N (2001) Midstratospheric ozone variability over bern related to planetary wave activity during the winters 1994-1995 to 1998-1999. J Geophys Res Atmos 106(D8):7903-7916. https://doi. org/10.1029/2000JD900710

Chandran A, Garcia RR, Collins RL, Chang LC (2013) Secondary planetary waves in the middle and upper atmosphere following the stratospheric sudden warming event of January 2012. Geophys Res Lett 40(9):1861-1867. https://doi.org/10.1002/grl.50373

De Mazière M, Thompson AM, Kurylo MJ, Wild J, Bernhard G, Blumenstock T, Hannigan J, Lambert J-C, Leblanc T, McGee TJ, Nedoluha G, 
Petropavlovskikh I, Seckmeyer G, Simon PC, Steinbrecht W, Strahan S, Sullivan JT (2017) The network for the detection of atmospheric composition change (ndacc): history, status and perspectives. Atmos Chem Phys Discuss 2017:1-40. https://doi.org/10.5194/acp-2017-402

Eckermann SD, Gibson-Wilde DE, Bacmeister JT (1998) Gravity wave perturbations of minor constituents: a parcel advection methodology. J Atmos Sci 55(24):3521-3539. https://doi.org/10.1175/1520-0469(1998) 055\%3c3521 :GWPOMC\%3e2.0.CO;2

Eriksson P, Jiménez C, Buehler SA (2005) Qpack, a general tool for instrument simulation and retrieval work. J Quant Spectrosc Radiat Transf 91 (1):4764. https://doi.org/10.1016/j.jgsrt.2004.05.050

Eriksson P, Buehler SA, Davis CP, Emde C, Lemke O (2011) Arts, the atmospheric radiative transfer simulator, version 2. J Quant Spectrosc Radiat Transf 112(10):1551-1558. https://doi.org/10.1016/j.jpsrt.2011.03.001

Eyring V, Dameris M, Grewe V, Langbein I, Kouker W (2003) Climatologies of subtropical mixing derived from $3 \mathrm{~d}$ models. Atmos Chem Phys 3(4):1007-1021. https://doi.org/10.5194/acp-3-1007-2003

Flury T, Hocke K, Haefele A, Kämpfer N, Lehmann R (2009) Ozone depletion, water vapor increase, and PSC generation at midlatitudes by the 2008 major stratospheric warming. J Geophys Res Atmos. https://doi. org/10.1029/2009JD011940

Flury T, Hocke K, Kämpfer N, Wu DL (2010) Enhancements of gravity wave amplitudes at midlatitudes during sudden stratospheric warmings in 2008. Atmos Chem Phys Discuss 10:29971-29995. https://doi. org/10.5194/acpd-10-29971-2010

Fritts DC, Alexander MJ (2003) Gravity wave dynamics and effects in the middle atmosphere. Rev Geophys. https://doi.org/10.1029/2001RG000106

Hocke K, Kämpfer N, Feist DG, Calisesi Y, Jiang JH, Chabrillat S (2006) Temporal variance of lower mesospheric ozone over Switzerland during winter 2000/2001. Geophys Res Lett. https://doi.org/10.1029/2005GL025496

Ingold T, Peter R, Kämpfer N (1998) Weighted mean tropospheric temperature and transmittance determination at millimeter-wave frequencies for ground-based applications. Radio Sci 33(4):905-918. https://doi. org/10.1029/98RS01000

Kämpfer N (1995) Microwave remote sensing of the atmosphere in Switzerland. Opt Eng 34(8):2413-2424. https://doi.org/10.1117/12.205666

Krüger K, Langematz U, Grenfell JL, Labitzke K (2005) Climatological features of stratospheric streamers in the fub-cmam with increased horizontal resolution. Atmos Chem Phys 5(2):547-562. https://doi.org/10.5194/ acp-5-547-2005
Manney GL, Michelsen HA, Bevilacqua RM, Gunson MR, Irion FW, Livesey NJ, Oberheide J, Riese M, Russell JM, Toon GC, Zawodny JM (2001) Comparison of satellite ozone observations in coincident air masses in early november 1994. J Geophys Res Atmos 106(D9):9923-9943. https://doi. org/10.1029/2000JD900826

Ming FC, Vignelles D, Jegou F, Berthet G, Renard J-B, Gheusi F, Kuleshov Y (2016) Gravity-wave effects on tracer gases and stratospheric aerosol concentrations during the 2013 ChArMEx campaign. Atmos Chem Phys Discuss. https://doi.org/10.5194/acp-2015-889

Moreira L, Hocke K, Eckert E, von Clarmann T, Kämpfer N (2015) Trend analysis of the 20-year time series of stratospheric ozone profiles observed by the gromos microwave radiometer at bern. Atmos Chem Phys 15(19):1099911009. https://doi.org/10.5194/acp-15-10999-2015

Moustaoui M, Teitelbaum H, Valero FPJ (2003) Ozone laminae inside the antarctic vortex produced by poleward filaments. Q J R Meteorol Soc 129(594):3121-3136. https://doi.org/10.1256/qj.03.19

Noguchi K, Imamura T, Oyama Kl, Bodeker GE (2006) A global statistical study on the origin of small-scale ozone vertical structures in the lower stratosphere. J Geophys Res Atmos. https://doi.org/10.1029/2006JD007232

Offermann D, Grossmann K-U, Barthol P, Knieling P, Riese M, Trant R (1999) Cryogenic infrared spectrometers and telescopes for the atmosphere (crista) experiment and middle atmosphere variability. J Geophys Res Atmos 104(D13):16311-16325. https://doi.org/10.1029/1998JD100047

Parrish A (1994) Millimeter-wave remote sensing of ozone and trace constituents in the stratosphere. Proc IEEE 82(12):1915-1929. https://doi. org/10.1109/5.338079

Peter R (1997) The ground-based millimeter-wave ozone spectrometer-gromos. IAP research report, University of Bern, Bern, Switzerland

Rodgers CD (1976) Retrieval of atmospheric temperature and composition from remote measurements of thermal radiation. Rev Geophys 14(4):609-624. https://doi.org/10.1029/RG014i004p00609

Waugh DW (1993) Subtropical stratospheric mixing linked to disturbances in the polar vortices. Nature 365(6446):535-537

Yamashita C, Liu HL, Chu X (2010) Gravity wave variations during the 2009 stratospheric sudden warming as revealed by ECMWF-T799 and observations. Geophys Res Lett. https://doi.org/10.1029/2010GL045437

Zhu X, Holton JR (1986) Photochemical damping of inertio-gravity waves. J Atmos Sci 43:2578-2584. https://doi.org/10.1175/1520-0469

\section{Submit your manuscript to a SpringerOpen ${ }^{\odot}$ journal and benefit from:}

- Convenient online submission

- Rigorous peer review

- Open access: articles freely available online

- High visibility within the field

- Retaining the copyright to your article

Submit your next manuscript at $\boldsymbol{\nabla}$ springeropen.com 